\title{
Avaliação do programa de monitoramento ambiental de empreendimentos aquícolas no Estado do Amazonas, Brasil
}

Evaluation of the environmental monitoring program of aquicultural enterprises in the State of Amazonas, Brazil

Evaluación del programa de monitoreo ambiental de emprendimientos acuícolas en el Estado de Amazonas, Brasil

Silva LCA, Machado-Bussons MR, Pantoja-Lima J. Avaliação do programa de monitoramento ambiental de empreendimentos aquícolas no Estado do Amazonas, Brasil. Rev Colombiana Cienc Anim. Recia. 2019; 11(2):Articulo713. DOI: https://doi.org/10.24188/recia.v11.n2.2019.713

Universidad de Sucre, Colombia

Los autores permiten a RECIA reimprimir el material publicado en él. En caso de que un autor quiera traducir o usar una publicación parcial o completa de nuestro Diario, el autor debe obtener un permiso por escrito del editor de la revista.

Revista Colombiana de Ciencia Animal - RECIA está distribuido bajo una Licencia Creative Commons Atribución-CompartirIgual 4.0 Internacional. 


\section{Avaliação do programa de monitoramento ambiental de empreendimentos aquícolas no Estado do Amazonas, Brasil}

Evaluation of the environmental monitoring program of aquicultural enterprises in the State of Amazonas, Brazil

Evaluación del programa de monitoreo ambiental de emprendimientos acuícolas en el Estado de Amazonas, Brasil

Carlos André Silva Lima M.Sc.

DOI: https://doi.org/10.24188/recia.v11.n2.2019.713

Universidade Federal do Amazonas (UFAM). Manaus; Brasil.

helter tgz@hotmail.com

(i) https://orcid.org/0000-0003-3862-0873

Márcia Regina Fragoso Machado-Bussons Ph.D.

Escola Superior Batista do Amazonas (ESBAM). Rua Leonor

Teles. Manaus, Brasil.

mmachadobussons@gmail.com

iD https://orcid.org/0000-0002-5038-1775

Jackson Pantoja-Lima Ph.D.

Instituto Federal de Educação do Amazonas (IFAM). Manaus, Brasil. jackson.lima@ifam.edu.br

Recepción: 23 Marzo 2019

DiD https://orcid.org/0000-0002-6449-4981

Aprobación: 16 Julio 2019

Publicación: 22 Julio 2019

\section{RESUMO}

0 presente artigo teve como objetivo avaliar o enquadramento legal para o uso e descarte de efluentes em corpos hídricos utilizados pela atividade aquícola no estado do Amazonas, por meio de acesso às informações de controle e monitoramento de parâmetros ambientais. 0 principal resultado foi obtido por meio dos laudos das análises de indicadores de qualidade da água, exigidos por um Programa de Monitoramento Ambiental (PMA) em empreendimentos que desenvolvem a atividade em condições que tornam o procedimento obrigatório para manutenção da licença ambiental, caso estes sejam classificados como de alto potencial de impactos ambientais pelo Órgão Estadual de Meio Ambiente (OEMA). De acordo com a legislação vigente, verificou-se que os principais parâmetros de variáveis físico-química dos empreendimentos pelo PMA encontravam-se dentro dos padrões aceitáveis permitidos. Não se descarta, porém, a cobrança da aplicação de melhores mecanismos de avaliação e controle de impactos ambientais como exigência para a regularização da atividade, como a aplicação de técnicas de Boas Práticas de Manejo (BPM's) e implantação de sistemas de tratamento de efluentes nos empreendimentos.

Palavras-chave: Controle ambiental, efluente, impacto ambiental, legislação.

\section{ABSTRACT}

The present article had as objective to evaluate the legal framework for the use and disposal of effluents in water bodies used by aquaculture activity in the state of Amazonas, through access to control information and monitoring of environmental parameters. The main result was obtained through the reports of the analysis of water quality indicators required by an Environmental Monitoring Program (PMA) in enterprises that develop the activity under conditions that make the procedure mandatory 
to maintain the environmental license, if they are classified as a high potential for environmental impacts by the State Environment Agency (SEA). According to the current legislation, it was verified that the main parameters of physical-chemical variables of the enterprises by the PMA were within the acceptable standards allowed. However, the application of better mechanisms for assessing and controlling environmental impacts is not ruled out as a requirement for regularization of the activity, such as the application of Best Management Practices (BMP) techniques and the implementation of effluent treatment systems in enterprises.

Keywords: Environmental control, Effluent, environmental impact, legislation.

\section{RESUMEN}

El presente artículo tuvo como objetivo evaluar el marco legal para el uso y disposición de los efluentes en cuerpos de agua utilizados por la actividad acuícola en el estado de Amazonas, a través del acceso a la información de control y el monitoreo de los parámetros ambientales. El resultado principal se obtuvo a través de los informes de análisis de indicadores de calidad del agua requeridos por un Programa de Monitoreo Ambiental (PMA) en empresas que desarrollan la actividad en condiciones que hacen que el procedimiento sea obligatorio para mantener la licencia ambiental, si se clasifican como un alto potencial de impacto ambiental por la Agencia Estatal de Medio Ambiente (AEMA). De acuerdo con la legislación vigente, se verificó que los parámetros principales de las variables físicoquímicas de las empresas por parte de la PMA estaban dentro de los estándares aceptables permitidos. Sin embargo, la aplicación de mejores mecanismos para evaluar y controlar los impactos ambientales no se descarta como un requisito para la regularización de la actividad, como la aplicación de técnicas de Buenas Prácticas de Manejo (BPM) y la implementación de sistemas de tratamiento de efluentes en proyectos

Palabras-clave: Control ambiental, efluente, impacto ambiental, legislación.

\section{INTRODUÇÃO}

A aquicultura é considerada uma atividade efetivamente poluidora que causa uma série de problemas ambientais e afeta o uso sustentável dos recursos naturais (1), provocando entre outros problemas, impactos diretos sobre a qualidade da água, como a eutrofização de corpos hídricos pela descarga de efluentes advindos da alimentação e excreção dos animais, e poluição por resíduos químicos utilizados em diferentes fazes do cultivo (2).

Como o crescimento da aquicultura tem acelerado o processo de eutrofização e gerado a necessidade de estudos dos efluentes provenientes da criação (3), pesquisas aplicadas são de extrema importância como forma de se minimizar os efeitos impactantes da interferência humana na qualidade das águas pela aquicultura, como por exemplo, o monitoramento das principais variáveis físico-químicas, bem como da vida aquática (4).

Para Souza (5) é importante se observar as variáveis físicas e químicas indicadoras de qualidade de água na aquicultura, por ser um instrumento no qual se determina não somente meios de garantia da sobrevivência dos animais e seu desenvolvimento - visto que a água em condições inadequadas ainda causa problemas no cultivo (6), mas garantir que os padrões de qualidade estabelecidos na legislação são atendidos.

Quanto a estes padrões, a Resolução do CONAMA no 357/2005 (7) é o instrumento legal brasileiro responsável pela sua definição, quantificação e aplicação para a qualidade dos cursos d'água, a qual estabelece o controle sobre as variáveis indicadoras de qualidade e as substâncias potencialmente prejudiciais aos seres vivos, conforme o uso a que é destinada a água, bem como os limites individuais de lançamento de substâncias, para avaliação do nível de poluição do ambiente impactado de acordo com as classes de corpos d'água, definidas conforme suas características específicas de utilização (art. $4^{\mathrm{o}}$ ). 
Segundo o art. 8 da Resolução do CONAMA n 357/2005, o Poder Público é o responsável por realizar a seleção, o monitoramento e o acompanhamento periódico desses parâmetros de qualidade de água, onde as cobranças de análises e avaliações dos resultados cabem ao órgão ambiental competente, bem como a sua aprovação e conformidade.

0 art. 9o da mesma Resolução, também esclarece que tais análises poderão ser realizadas por laboratório próprio, conveniado ou contratado, onde deverão ser adotados todos os procedimentos de controle de qualidade analítica necessários ao atendimento das condições exigíveis, garantindo-se desta forma a confiança necessária aos resultados.

Assim, o presente trabalho tem como objetivo analisar os resultados das variáveis indicadoras de qualidade de água apresentados como medida para o monitoramento da qualidade ambiental da aquicultura no estado do Amazonas, considerando como critério o enquadramento dos limites de lançamentos definidos pela legislação vigente, discutindo sua eficiência como ferramenta de controle de impactos ambientais para regularização da atividade.

\section{MATERIAIS E MÉTODOS}

O estudo foi realizado através do levantamento de informações dos laudos de análises físico-químicas de qualidade de água de empreendimentos de pisciculturas cadastrados junto ao Instituto de Proteção Ambiental do Amazonas - IPAAM (Brasil), os quais são produzidos por laboratórios credenciados e apresentados ao referido Órgão Estadual de Meio Ambiente (OEMA) responsável pela regularização de atividades potencialmente ou efetivamente poluidoras no estado do Amazonas.

Os laudos são exigidos obrigatoriamente pelos empreendimentos de grande potencial poluidor como exigência complementar à implementação de um Programa de Monitoramento Ambiental (PMA), que é o critério técnico de avaliação de impactos ambientais para manutenção e/ou renovação da Licença Ambiental no estado, conforme legislação vigente.

Buscou-se, através dos resultados de análises, avaliar as variáveis de qualidade da água e suas alterações, por meio de padrões indicadores das águas de abastecimento e de lançamentos dos efluentes resultantes da atividade, comparando com os padrões indicadores de qualidade da água e de substâncias potencialmente prejudiciais aos seres vivos, para o enquadramento legal desses resultados de acordo com a classe de uso de referência dos corpos hídricos, com seus limites de concentração de emissões dos efluentes definidos pela Resolução CONAMA № 430/2011 (8) e Resolução CONAMA № 357/2005 (7).

Foram identificados, levantados e reunidos os laudos de qualidade da água apresentados entre período de junho de 2007 - data da obrigatoriedade da apresentação dos laudos - até dezembro de 2017 para as avaliações de resultados. Os valores das variáveis físico-químicas de qualidade de água apresentadas nos laudos de monitoramento foram coletados e armazenadas em um banco de dados, posteriormente agrupados em planilhas para o tratamento e interpretação na forma de gráficos e tabelas. $O$ estudo utilizou nas interpretações dos resultados análises de aspectos quantitativos, pela identificação da ocorrência de alterações dos padrões ambientais (parâmetros de qualidade da água), através da determinação da frequência dessa ocorrência pelos empreendimentos levantados.

\section{RESULTADOS}

Identificou-se, através dos critérios de porte (pequeno, médio ou grande), sistema de cultivo (extensivo, semi-intensivo ou intensivo) e espécie (autóctone, alóctone ou exótica) estabelecidos pela legislação (9), que de um total de 1.353 empreendimentos registrados junto ao órgão ambiental durante o período de coleta, somente 77 (5.69\%) são classificados como de grande potencial poluidor, e, portanto, possuem como obrigatoriedade a implementação de um Programa de Monitoramento Ambiental (PMA). 
A tabela 1 apresenta o conjunto de características dos empreendimentos identificados com laudos de análises de qualidade de água utilizados no levantamento, no qual todos (100\%) possuem como atributo a condução da atividade na modalidade de piscicultura de água doce, em monocultivo, e com as espécies autóctones regionais ambaqui Colossoma macropomum (Cuvier, 1818), matrinxã Brycon amazonicus (Spix \& Agassiz,1829) ou pirarucu Arapaima gigas (Schinz, 1822).

Também verificou-se que $76.62 \%$ dos empreendimentos utiliza sistema semi-intensivo, onde em todos (100\%) que são classificados como de terra firme (viveiros escavados e barragens) são aplicadas medidas de Boas Práticas de Manejo (BPM's), com adubação, calagem e alimentação frequentes. Para os empreendimentos de tanques-rede e fluxo contínuo é aplicado somente o fornecimento de ração como medida de manejo.

Tabela 1. Classificação dos empreendimentos aquícolas de acordo com as características de sistema de cultivo e tipo de dispositivo existente.

\begin{tabular}{|c|c|c|c|c|c|c|c|c|c|c|c|}
\hline \multirow{3}{*}{ Sistema de cultivo } & \multicolumn{9}{|c|}{ Tipo de dispositivo } & \multirow{3}{*}{ Total } & \multirow{3}{*}{ (\%) } \\
\hline & \multicolumn{3}{|c|}{$\begin{array}{c}\text { Viveiro escavado/ } \\
\text { Barragem }\end{array}$} & \multicolumn{3}{|c|}{ Tanque-rede/Gaiola } & \multicolumn{3}{|c|}{ Fluxo-contínuo } & & \\
\hline & $\mathbf{P}$ & $\mathbf{M}$ & G & $\mathbf{P}$ & $\mathbf{M}$ & G & $\mathbf{P}$ & $\mathbf{M}$ & G & & \\
\hline Extensivo & 0 & 0 & 0 & 0 & 0 & 0 & 0 & 0 & 0 & 0 & 0.00 \\
\hline Semi-intensivo & 1 & 56 & 2 & 0 & 0 & 0 & 0 & 0 & 0 & 59 & 76.62 \\
\hline Intensivo & 11 & 1 & 0 & 0 & 0 & 1 & 0 & 3 & 2 & 18 & 23.38 \\
\hline Total & 12 & 57 & 2 & $\mathbf{0}$ & $\mathbf{0}$ & 1 & $\mathbf{0}$ & 3 & 2 & 77 & 100.00 \\
\hline
\end{tabular}

Nota: P - Pequeno; M - Médio; G - Grande.Fonte: Dados da pesquisa (2017).

Para todos os empreendimentos identificados com PMA, constata-se que somente $27.27 \%$ utiliza algum tipo de sistema de tratamento de efluentes, sendo que deste total, $22.08 \%$ utilizam o filtro mecânico. Observa-se ainda que para 84.42\% (65 empreendimentos) a destinação da água é o ambiente natural, dos quais $75.38 \%$ ( 49 empreendimentos) ocorrem sem nenhum tipo de tratamento prévio (Tabela 2).

Tabela 2. Classificação dos empreendimentos aquícolas com PMA, sistemas de tratamento de efluentes e destinação da água utilizados após o uso na atividade.

\begin{tabular}{cccccc}
\hline \multirow{2}{*}{ Sistema de tratamento } & \multicolumn{3}{c}{ Destinação da água } & Total & \multirow{2}{*}{ (\%) } \\
\cline { 2 - 5 } & Ambiente natural & Reaproveitamento & Outros usos & 2 & 17 \\
Filtro mecânico & 12 & 3 & 0 & 22.08 \\
Tanques de decantação & 3 & 0 & 0 & 3.90 \\
Biofiltro & 1 & 0 & 0 & 1 & 56 \\
Não utiliza & 49 & 7 & $\mathbf{2}$ & $\mathbf{7 7}$ & $\mathbf{1 0 0 . 0 0}$ \\
Total & $\mathbf{6 5}$ & $\mathbf{1 0}$ & & 2.73 \\
\hline
\end{tabular}

Fonte: Dados da pesquisa (2017).

A tabela 3 reúne os resultados de levantamento dos laudos de análises físico-químicas de qualidade da água como procedimentos para o atendimento às exigências de monitoramento ambiental, nos quais se verifica uma maior preocupação quanto ao monitoramento dos lançamentos dos efluentes no ambiente natural (77.92\%), o que pode refletir um maior comprometimento quanto ao atendimento à legislação, como reflexo da cobrança pela autoridade ambiental no estado. Porém, evidencia-se ainda a ocorrência do não atendimento dessa exigência como fator de manutenção das Licenças Ambientais. 
Tabela 3. Relação de empreendimentos com PMA que possuem análises dos parâmetros de qualidade de água por categoria de origem (entrada e saída).

\begin{tabular}{ccccc}
\hline \multirow{2}{*}{ Situação } & \multicolumn{2}{c}{ Entrada (Abastecimento) } & \multicolumn{2}{c}{ Saída (Efluentes) } \\
\cline { 2 - 5 } & Quantidade & Frequência (\%) & Quantidade & Frequência (\%) \\
\hline Com análise & 15 & 19.48 & 60 & 77.92 \\
Sem análise & 62 & 80.52 & 17 & 22.08 \\
Total & $\mathbf{7 7}$ & $\mathbf{1 0 0 . 0 0}$ & $\mathbf{7 7}$ & $\mathbf{1 0 0 . 0 0}$ \\
\hline
\end{tabular}

Fonte: Dados da pesquisa (2017).

Sobre os parâmetros indicadores, de acordo com os procedimentos administrativos e termos de referência definidos pelo OEMA para a avaliação de controle de qualidade da água em aquicultura no estado do Amazonas, os seguintes parâmetros de análises físico-químicas da água são exigidos como parte do PMA para regularização da atividade: Oxigênio Dissolvido (O.D.) (mg/l); pH; Temperatura $\left({ }^{\circ} \mathrm{C}\right)$; Amônia $\left(\mathrm{NH}_{3}+\mathrm{NH}_{4+}\right)(\mathrm{mg} / \mathrm{l})$; Nitrato $\left(\mathrm{NO}_{3}\right)(\mathrm{mg} / \mathrm{l})$; Nitrito $\left(\mathrm{NO}_{2}\right)(\mathrm{mg} / \mathrm{l})$; Fósforo Total $(\mathrm{P})$ (mg/l); DBO5 (mg/l); Sólidos Suspensos Totais (mg/l); Clorofila a ( $\mu \mathrm{g} / \mathrm{l})$, e Turbidez (UNT).

Utilizando-se como referência a Resolução CONAMA no 357/2005, que estabelece limites de substâncias em corpos hídricos e a Resolução CONAMA no 430/2011, que em sua substituição, estabelece novos limites para lançamento de efluentes em corpos hídricos, e ainda considerando que estes valores são determinados pela classificação dos corpos hídricos de uso direto na aquicultura continental em águas doces, classificadas como de Classe II (art. 4ํㅜ, inciso III da Resolução do CONAMA no 357/2005), foram reunidos na tabela 4 os limites de concentração de substâncias para determinação da qualidade da água, considerados em função de suas características intrínsecas de variáveis de entrada (fontes de abastecimento) e saída (efluentes lançados), bem como a quantidade de análises efetuadas e os valores médios dos resultados.

Tabela 4. Limites de parâmetros de qualidade de água doce (Classe II), quantidade de análises e média dos resultados das variáveis físicas e químicas da água nas entradas (abastecimento) e saídas (efluentes) dos empreendimentos analisados, com respectivo controle na legislação.

\begin{tabular}{|c|c|c|c|c|c|c|}
\hline \multirow{2}{*}{ Parâmetro } & \multicolumn{3}{|c|}{ Entrada (Abastecimento) } & \multirow[b]{2}{*}{ Análises } & \multicolumn{2}{|c|}{ Saída (Efluentes) } \\
\hline & Análises & Resultado & Controle $^{1}$ & & Resultado & Controle $^{2}$ \\
\hline O.D $\left(\mathrm{O}_{2}\right)(\mathrm{mg} / \mathrm{l})$ & 11 & $6.4 \pm 1.6$ & 5,0 & 47 & $5.6 \pm 1.5$ & 5.0 \\
\hline $\mathrm{pH}$ & 14 & $5.60 \pm 0.64$ & 5,0 a 9,0 & 59 & $5.99 \pm 0.87$ & 5.0 a 9.0 \\
\hline Temperatura $\left({ }^{\circ} \mathrm{C}\right)$ & 11 & $24.9 \pm 8.5$ & $\mathrm{~N} / \mathrm{A}^{*}$ & 37 & $28.4 \pm 3.0$ & 40.0 \\
\hline Amônia $\left(\mathrm{NH}_{3}+\mathrm{NH}_{4+}\right)(\mathrm{mg} / \mathrm{l})$ & 15 & $0.064 \pm 0.085$ & 2.0 & 58 & $0.765 \pm 2.058$ & 20.0 \\
\hline Nitrato $\left(\mathrm{NO}_{3}\right)(\mathrm{mg} / \mathrm{l})$ & 8 & $0.921 \pm 1.350$ & 10.0 & 30 & $2.189 \pm 1.753$ & 10.0 \\
\hline Nitrito $\left(\mathrm{NO}_{2}\right)(\mathrm{mg} / \mathrm{l})$ & 11 & $0.029 \pm 0.060$ & 1.0 & 38 & $0.121 \pm 0.216$ & 1.0 \\
\hline Fósforo total (F) (mg/l) & 12 & $0.023 \pm 0.06$ & 0.10 & 50 & $0.123 \pm 0.333$ & 0.10 \\
\hline DBO5 (mg/l) & 3 & $11.60 \pm 15.30$ & 5.0 & 15 & $13.318 \pm 16.62$ & 5.0 \\
\hline Sólidos totais (mg/l) & 9 & $18.27 \pm 33.36$ & 500.0 & 23 & $141.68 \pm 505.56$ & 500.0 \\
\hline Clorofila $a(\mu \mathrm{g} / \mathrm{l})$ & 0 & - & 30.0 & 0 & - & 30.0 \\
\hline Turbidez (UNT**) & 11 & $13.74 \pm 12.27$ & 100.0 & 49 & $37.82 \pm 54.45$ & 100.0 \\
\hline
\end{tabular}

1. Parâmetros estabelecidos pela Resolução CONAMA no 357/2005 (Classe II).

2. Parâmetros estabelecidos pela Resolução CONAMA no 430/2011 (Classe II).

*N/A - Não avaliado.

**UNT - Unidade Nefelométrica de Turbidez.

Fonte: Dados da pesquisa (2017).

Quanto à análise individual das variáveis de qualidade de água de abastecimento (entrada), observase através da figura 01 a sua baixa ocorrência, onde as variáveis amônia, com 15 análises (19.48\%), pH, com 14 análises (18.18\%) e fósforo, com 12 análises (15.58\%), foram as que mais se destacaram positivamente. Sobre os dados de saída (efluente), destacam-se maiores ocorrências das variáveis $\mathrm{pH}$ (59 análise) (76.62\%), amônia (58 análises) (75.32\%) e fósforo (50 análises) (64.94\%). 


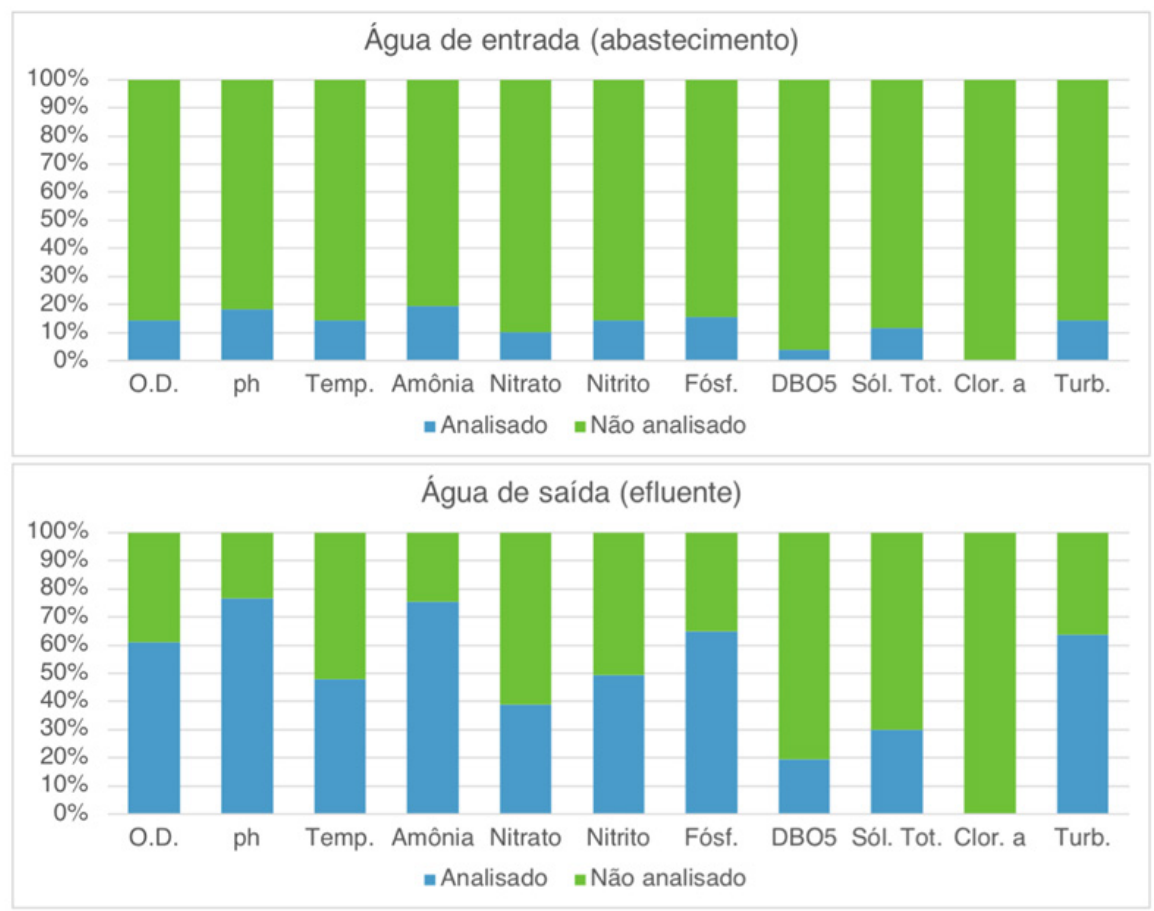

Figura 1. Participação da ocorrência de análises de qualidade da água de entrada (abastecimento) e saída (efluente) por categoria de parâmetro indicador.

Fonte: Dados da pesquisa (2017).

Ao se enquadrar os resultados aos valores de padrões estabelecidos pela legislação (8) para corpos d'água de Classe II, pode-se constatar que de um total de 11 variáveis, quatro (36.36\%) apresentaram resultados com alterações na fonte de entrada (abastecimento) e seis (54.55\%) apresentam alterações nos limites dos lançamentos de saída (efluentes) para os empreendimentos analisados (Figura 2).

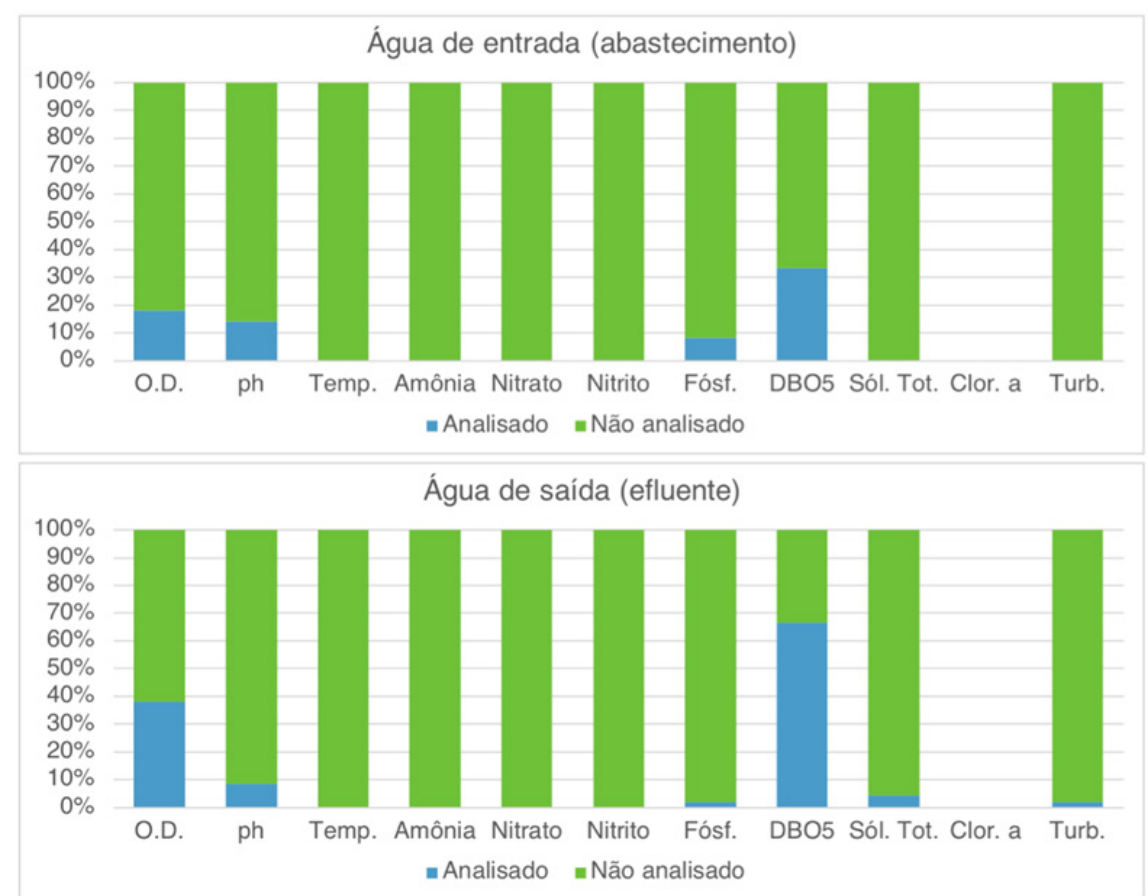

Figura 2. Participação da ocorrência de alterações nas análises de qualidade da água de entrada (abastecimento) e saída (efluente) por categoria de parâmetro indicador.

Fonte: Dados da pesquisa (2017).

Com relação às análises individuais, a Demanda Bioquímica de Oxigênio (DB05) apresentou alterações de qualidade daágua de abastecimento (entrada) em um (33.33\%) empreendimento e de saída (efluentes) em dez (66.67\%). O DB05 apresentaram valores médios obtidos na faixa de $11.60 \pm 15.30 \mathrm{mg} / \mathrm{l}$ nos resultados de entrada (abastecimento), e 13.318 $\pm 16.62 \mathrm{mg} / \mathrm{l}$ para os resultados de saída (efluentes) (Tabela 4). 
Verifica-se que valores inferiores a $5.0 \mathrm{mg} / \mathrm{l}$ de O.D. ocorrem em apenas dois (18.18\%) empreendimento com análise de entrada (abastecimento) e 18 (38.30\%) empreendimentos com análises de saída (efluentes), estabelecendo este como o segundo maior parâmetro com alterações ambientais entre os 11 investigados. As médias dos resultados ficaram em $6.4 \pm 1.6 \mathrm{mg} / \mathrm{l}$ para entrada (abastecimento) e $5.6 \pm 1.5 \mathrm{mg} / \mathrm{l}$ para saída (efluentes).

Outras variáveis apresentaram valores com alteração, porém com menor ocorrência. Valores de entrada (abastecimento) apresentaram alterações somente para o parâmetro de análise do fósforo total (8.33\%), com valor médio de $0.023 \pm 0.06 \mathrm{mg} / \mathrm{l}$. Quanto às variáveis de saída (efluentes), os sólidos totais (4.35\%), a turbidez (2.04\%) e o fósforo total (2.00\%) apresentaram ocorrência de alterações quanto ao que preconiza a legislação. Os valores médios apresentados para estes indicadores foram $141.68 \pm 505.56 \mathrm{mg} / \mathrm{l}$ para sólidos totais, $37.82 \pm 54.45 \mathrm{mg} / \mathrm{l}$ para turbidez e $0.123 \pm 0.333 \mathrm{mg} / \mathrm{l} \mathrm{de}$ fósforo total.

\section{DISCUSSÃo}

É baixa a ocorrência do uso de mecanismos de controle e monitoramento da qualidade da água para as variáveis de entrada nos empreendimentos, bem como o uso de métodos de controle de contaminações de descarte para os lançamentos dos efluentes, o que caracteriza a pouca preocupação dos responsáveis em aplicar medidas ambientais preventivas, influenciando negativamente no desenvolvimento dos animais e podendo provocar conflitos quanto ao direito de uso de corpos hídricos na atividade.

Sobre os resultados, Silva (10) expõe que a avaliação da qualidade, quantidade e origem da água utilizada na atividade aquícola devem ser observadas e investigadas pelo empreendedor, devendo obedecer às normas e parâmetros de exigência dos projetos, necessários para suprir as necessidades do empreendimento.

Emgeral,a qualidade daágua do cultivo seráinfluenciada pelas características daágua deabastecimento, como: produtividade primária, concentração de material orgânico, elementos químicos e presença de microrganismos, em especial coliformes, além de uma relação com a constituição do solo de origem e/ou percurso percorrido pela água (3). Muitas vezes, a aquicultura é afetada pela poluição da água resultante de outros usuários (2).

Uma boa avaliação para o conhecimento da qualidade da água de origem pode fornecer informações que determinem a natureza de sua utilização e manutenção no ambiente de criação na piscicultura. No entanto, o resultado demonstra que é baixo o interesse deste fator no controle dos empreendimentos analisados, o que caracteriza risco na condução da atividade no estado.

Sobre os dados de saída (efluentes), verifica-se uma maior preocupação quanto ao atendimento das exigências de monitoramento dos lançamentos dos efluentes no ambiente natural. 0 resultado pode refletir um maior comprometimento no que refere-se ao atendimento à legislação, como reflexo da exigência de cobrança da análises pela autoridade ambiental no estado, e consequente fator de avaliação para manutenção das Licenças Ambientais.

Constata-se pela análise individual das variáveis de qualidade de água, tanto de abastecimento (entrada) quanto de lançamento (saída), que nenhum empreendimento avaliou todos os 11 parâmetros mínimos de análise exigidos, o que caracteriza o não cumprimento de determinações estabelecidas pelo OEMA para manutenção da Licença Ambiental no Amazonas.

Deve-se destacar, no entanto, que apesar de se evidenciar a ocorrência do não atendimento dessa exigência como medida para regularização ambiental, não foi intensão deste estudo, verificar o estado de regularidade dos empreendimentos levantados, no qual estes permanecem passíveis, pelo não cumprimento das solicitações de estudos e informações mínimas pelo OEMA responsável, de sanções previstas na legislação vigente caso caracterizada irregularidade ambiental. 
A Resolução CONAMA no 430/2011 (8) estabelece que para corpos d'água de Classe II, são permitidos os lançamentos de efluentes, desde que obedeçam aos valores máximos de emissão estabelecidos. 0 art. 6º, inciso IV, da Lei Estadual no 3.802/2012 (11) determina que é considerada uma irregularidade ambiental o lançamento de água efluente fora dos padrões estabelecidos pela legislação, onde todo uso de recursos hídricos e lançamentos de efluentes em corpo d'água, oriundos dos empreendimentos aquícolas deverá estar de acordo com a legislação pertinente (art. 7ํㅜ).

Considerando esta determinação, observa-se, ao se analisar individualmente as variáveis de qualidade de água nos empreendimentos levantados, a ocorrência de alterações com maior frequência na Demanda Bioquímica de Oxigênio (DB05) tanto para entrada (abastecimento) quanto para saída (efluentes), ou seja, os resultados de análise de DB05 ultrapassaram valores de 5,0 mg/l conforme a legislação específica.

A DBO é a medida da quantidade de oxigênio consumido no processo biológico de oxidação da matéria orgânica na água, o qual se constitui em um importante indicador de qualidade das águas naturais. A determinação da DBO é feita em laboratório, observando-se o oxigênio consumido em amostras do líquido, durante 5 dias, a temperatura de $20^{\circ} \mathrm{C}$, onde indica a magnitude do consumo de oxigênio (mg/l) pelas bactérias na decomposição da matéria orgânica (12).

Grandes quantidades de matéria orgânica, oriunda de sólidos e nutrientes dissolvidos, utilizam grandes quantidades de oxigênio. Portanto, quanto maior o grau de poluição, maior serã a DBO (10). Em um ambiente de criação, sólidos e nutrientes dissolvidos originam-se de alimentos não consumidos, fezes produzidas pelo metabolismo dos peixes, sólidos transportados com o fluxo da fonte de água externa, e o crescimento de microalgas e bactérias (13).

Deste modo, pode-se inferir que a ocorrência de alterações de entrada (abastecimento) desta variável indica a existência de baixa qualidade de água em alguns ambientes de captação da água para o cultivo. Também se pode deduzir, pela ocorrência de alterações dessa variável na saída (efluente) nos sistemas, o indicativo de poluição da qualidade da água dos lançamentos nos empreendimentos identificados, possivelmente pela concentração de carga orgânica em consequência da má aplicação de técnicas de manejo e alimentação.

Quanto ao oxigênio dissolvido (O.D.), considera-se que este é o parâmetro físico-químico mais importante no desenvolvimento da aquicultura. Este gás funciona como um fator limitante sobre o crescimento, podendo ser mais importante em muitos casos até que o próprio alimento, no qual a sua concentração mínima deve ser mantida acima de $5.0 \mathrm{mg} / \mathrm{l}$ conforme determina a Resolução CONAMA no 430/2011 (8), sendo que quando esta concentração chega a valores abaixo de $2.0 \mathrm{mg} / \mathrm{l}$ pode ocorrer excessivo estresse e mortalidade de peixes (12).

A deficiência de concentrações de oxigênio pode ser um indicador de baixa produção primária (fitoplâncton) como fonte produtora desse composto na água, ou pode ainda indicar a aplicação de elevadas taxas de adensamento de animais em viveiros de criação que favorecem o consumo e deficiência no sistema. Com base na análise de médias dos resultados (Tabela 3), os valores de entrada (abastecimento) e saída (efluentes) para O.D. ficaram com faixas médias de resultados considerados acima do que é recomendado para o cultivo, e dentro dos valores aceitáveis para qualidade da água de uso e descarte no ambiente.

O pH é um importante indicador da estabilidade química da água. Seus valores devem variar de 6 a 9, sendo 7 a neutralidade do meio (14). A elevação do $\mathrm{pH}$ aumenta a concentração da forma não iônica da amônia, ou seja, a fração tóxica da amônia na água $\left(\mathrm{NH}_{3}\right)$. Valores inferiores a 7 a fração de $\mathrm{NH}_{4+}$ da reação de equilíbrio será predominante. Em pH mais alcalino ocorre maior transformação do íon amônio $\left(\mathrm{NH}_{4+}\right)$ em amônia livre e gasosa $\left(\mathrm{NH}_{3}\right)$, tóxica aos peixes (15).

Sobre os resultados, o pH foi considerado o terceiro maior parâmetro com alteração, tanto para análises de entrada (abastecimento) quanto para saída (efluentes), onde os resultados com alterações ficaram com faixa abaixo de 5, o que indica ocorrência de águas ácidas, que é desfavorável ao cultivo (16). 
Pode-se considerar os valores dos resultados de análises de $\mathrm{pH}$ com baixa ocorrência, porém com importância significativa, na medida que resultados inadequados desse parâmetro podem indicar alterações ambientais em desacordo com a legislação, impedido ou restringindo a manutenção da autorização (licença) ambiental, além de provocar alterações que comprometem o cultivo nos empreendimentos, ou ainda a manutenção da vida de organismos aquáticos, considerada incompatível em ambientes de corpos hídricos receptores dos lançamentos pós descarte.

Para Eler \& Millani (17), o efeito da qualidade do efluente sobre o corpo receptor está ligado principalmente à quantidade de sólidos suspensos na água, à quantidade de nutrientes dissolvidos e à redução nas concentrações de oxigênio dissolvido. No lançamento de efluentes, eles podem sedimentar-se no leito dos rios destruindo organismos que fornecem alimentos ou também danificar os leitos de desova de peixes. Os sólidos podem reter bactérias e resíduos orgânicos nos fundos dos viveiros promovendo a decomposição anaeróbia (anaerobiose) (10).

Conforme Boyd et al. (2) esclarecem, efluentes de aquicultura contêm nutrientes, principalmente partículas do solo em suspensão e partículas e matéria orgânica dissolvida. Estas partículas podem aumentar a turbidez e causar sedimentação em águas receptoras. A principal fonte de sólidos advém do alimento não convertido em massa para os peixes, podendo chegar até $40 \%$ em material em suspensão na água e que logo se depositará no fundo dos viveiros. Assim, a baixa qualidade da ração nos tanques e viveiros eleva a concentração de nutrientes na água e sedimento.

Verifica-se que os resultados de sólidos totais ficaram com valores abaixo do que é permitido pela legislação ( $500.0 \mathrm{mg} / \mathrm{l}$ ) na maioria dos empreendimentos analisados (95.65\%), o que evidencia o resultado da aplicação das medidas de Boas Práticas de Manejo (BPM's), principalmente como relação à qualidade e técnicas de administração de ração. Outros resultados que corroboram esta evidência é a baixa ocorrência de valores alterados para os parâmetros turbidez (2.04\%) e fósforo (2.00\%) da água dos efluentes (2).

Um dos principais impactos causados durante a fase de operação do cultivo é a liberação de efluentes ricos em nutrientes (principalmente nitrogênio e fósforo), que causam eutrofização em corpos d'água naturais (18). A dinâmica desses nutrientes principalmente tem efeito direto na biota aquática, interferindo no crescimento e desenvolvimento dos organismos planctônicos e macróbias (4).

O fósforo é um nutriente que faz parte de alguns processos metabólicos importantes, tais como: fotossíntese, respiração e síntese proteica; sendo, portanto, um elemento essencial na cadeia alimentar dos ecossistemas aquáticos (10). A emissão de fósforo varia em função da retenção deste composto pelos peixes produzidos, das práticas zootécnicas adotadas e da qualidade das rações utilizadas $(18,19)$. Fontes de fósforo em efluentes de aquiculturas são originados da ração não consumida, e processos de excreção (fezes e urina).

O fósforo, também pode ser introduzido no ambiente através de fertilização química ou orgânica, onde em um manejo inadequado, principalmente em águas naturalmente mesotróficas, poderá levar a um processo rápido de eutrofização (10). Assim, sugere-se que baixa ocorrência de alterações deste parâmetro nos resultados apurados pode indicar que estão sendo aplicadas além da alimentação, técnicas adequadas de adubação dos viveiros, e consequentemente esses efeitos sendo refletidos nos valores de lançamentos dos efluentes.

A identificação da concentração de amônia total $\left(\mathrm{NH}_{3}+\mathrm{NH}_{4+}\right)$, nitrito $\left(\mathrm{NO}_{2}\right.$-) e nitrato (NO3-) com valores inferiores ao que preconiza a legislação, tanto em parâmetros de entrada (abastecimento) quanto de saída (efluentes), confirmam, assim como nos resultados de sólidos totais, turbidez e fósforo, a eficácia da implementação de BPM's para condução adequada da atividade, e que estes resultados contribuíram para a reduzida ocorrência de alterações dos padrões de qualidade da água em corpos hídricos receptores.

A amônia é o principal resíduo nitrogenado excretado pelos peixes, resultante do metabolismo proteico, e contribui para o aumento da decomposição microbiana de resíduos orgânicos (restos de alimentos, fezes e adubos orgânicos) $(3,20)$. Dentre os compostos nitrogenados dissolvidos na água, encontra-se uma forma ionizada $\left(\mathrm{NH}_{4+}\right)$, denominada íon amônio, ou simplesmente amônio, e outra não ionizada $\left(\mathrm{NH}_{3}\right)$, conhecida como amônia. As duas formas juntas constituem a amônia total ou nitrogênio amoniacal total (10). No entanto, a forma não ionizada da amônia $\left(\mathrm{NH}_{3}\right)$ é a mais tóxica para os organismos aquáticos (20). 
O nitrogênio dos efluentes das atividades de aquicultura é originado principalmente da proteína da ração, sendo que parte é excretada pelos organismos na forma de amônia, enquanto o restante é eliminado pelas fezes na forma de nitrogênio orgânico (21). Assim como ocorre com o fósforo, o uso de rações de baixa qualidade, somado a um manejo alimentar inadequado, afeta diretamente a qualidade da água e aumenta a concentração de amônia nos viveiros de aquicultura (20).

Quanto ao enriquecimento pelo fósforo e nitrogênio, o maior problema é que eles agem como substâncias fertilizantes, estimulando o crescimento do fitoplâncton (17). Em decorrência disto, à medida que as concentrações de nutrientes aumentam, há aceleração da produtividade de algas, alterando a ecologia do sistema aquático (3).

Elevados valores de clorofila $a$ indicam o aumento da população fitoplanctônica proporcionado pelo acúmulo de nutrientes, notadamente o nitrogênio e fósforo (22). Assim, a avaliação de tais resultados seria de extrema valia para se indicar a presença desses compostos na água. No entanto, embora a literatura referente à aquicultura esteja repleta de referências sobre produtividade primária e clorofila $a$, é raro medir essas duas variáveis (20). Verifica-se que a não realização de análises desse parâmetro por nenhum empreendimento confirma a afirmação do autor, e torna claro a sua importância para a determinação da presença destes compostos como indicadores de poluição ambiental.

\section{CONCLUSÃO}

Os resultados obtidos através do levantamento dos parâmetros indicadores de qualidade das águas de uso e dos lançamentos de efluentes para empreendimentos aquícolas de alto potencial de impactos ambientais no estado do Amazonas, indicam que mesmo sem a aplicação de métodos de monitoramento e controle dos lançamentos de efluentes na atividade, são ambientalmente aceitáveis os valores de variáveis no que concerne aos padrões estabelecidos na legislação vigente, sendo que estes se encontram em sua maioria dentro de limites definidos como admissíveis para o cultivo de animais aquáticos.

Constata-se ainda, no que se refere ao descumprimento da obrigatoriedade de apresentação das análises físico-químicas de qualidade de água por parte dos empreendimentos, a falha no atendimento às exigências impostas pelo órgão licenciador responsável, evidenciando que procedimentos adequados de avaliação de impactos ambientais requerem melhores mecanismos de cobrança para a regularização da atividade, sendo estes necessários para o monitoramento apropriado desses empreendimentos considerado como de grande porte, ou de alto potencial poluidor, conforme definidos em normas.

Torna-se evidente que procedimentos de análises de padrões de qualidade da água são ferramentas eficiente de avaliação de impactos e diagnósticos ambiental na condução da aquicultura, sendo de grande importância como indicadores para se determinar níveis de poluição pelo uso dos recursos hídricos, onde este pode ser considerado o principal fator para determinação do sucesso no desenvolvimento da atividade.

Ressalta-se que apesar de os empreendimentos estarem em sua maioria dentro dos padrões estabelecidos pela legislação, não deve ser eliminada a possibilidade de implementação de outras medidas de redução de impactos ambientais na atividade, como a cobrança de estudos pautados em Programas de Monitoramento Ambiental (PMA) que incluam a aplicação de Boas Práticas de Manejo (BPM's) e uso de sistemas de tratamento de efluentes, onde estas exigências podem produzir melhores resultados de avaliação e monitoramento de impactos em empreendimentos considerados potencialmente ou efetivamente mais poluidores, bem como podem trazer melhores índices de desempenho zootécnico nos cultivos.

\section{Agradecimentos}

Os autores agradecem ao Instituto de Proteção Ambiental do Amazonas - IPAAM, pelo apoio na disponibilização dos dados. Ao programa de PPG-CIPET pela oportunidade de realizar o presente estudo. Â Fundação de Amparo à Pesquisa no Estado do Amazonas, por concessão de bolsa ao orientador. 


\section{REFERÊNCIAS}

1. Ottinger M, Clauss KC, Kuenzer C. Aquaculture: Relevance, distribution, impacts and spatial assessments - A review. Ocean \& Coastal Management 2016; 119:244-266. DOI: https://doi. org/10.1016/j.ocecoaman.2015.10.015

2. Boyd CE, Lim C, Queiroz JF, Salie K, Wet L, McNevin A. Best Management Practices for Responsible Aquaculture. Aquaculture CRSP, Oregon State University, Corvallis: Oregon; 2008. URL Available in: http://pdacrsp.oregonstate.edu/pubs/featured titles/boyd.pdf

3. Macedo CF, Sipaúba-Tavares LH. Eutrofização e qualidade da água na piscicultura: consequências e recomendações. Bol Inst Pesca, São Paulo. 2010; 36(2):149-163. URL Available in: https:// www.pesca.sp.gov.br/

4. Millan RN. Dinâmica da qualidade da água em tanques de peixes de sistema pesque-pague: aspectos físico-químicos e plâncton. [Tesis M.Sc]. Universidade Estadual Paulista, Centro de Aqüicultura, Jaboticabal, SP: Brasil; 2009. URL Available in: http://hdl.handle.net/11449/86751

5. Souza A da S. Análise de desenvolvimento do tambaqui, Colossoma macropomum (Cuvier) 1818 (Pisces, Serrasalmidae), utilizando a massa de mandioca branca, manihot esculenta (Crantz) como complemento alimentar em viveiros de piscicultura em área de várzea. [Tesis M.Sc]. Universidade Federal do Pará. Instituto de Ciências Agrárias. Pará: Belém, PA, Brasil; 2009. URL Available in: http://cienciaanimal.ufpa.br/pdfs/CA Ciencia Animal/CA ALEX DA SILVA LOBAO DE SOUZA.pdf

6. Stachiw R, Silva FR, Vendrusculo J, Medeiros, TF, Tavares, VCC, Dutra, AR. Qualidade da água de tanques de piscicultura em Rolim de Moura - RO. Revista Brasileira de Ciências da Amazônia, v2, n1, p. 22-34, 2013. URL Available in: http://www.periodicos.unir.br/index.php/rolimdemoura/ article/view/797/834

7. RESOLUÇÂO CONAMA no. 357, de 17 de março de 2005. Dispõe sobre a classificação dos corpos de água e diretrizes ambientais para o seu enquadramento, bem como estabelece as condições e padrões de lançamento de efluentes, e dá outras providências. Diário Oficial da União. CONAMA (Conselho Nacional do Meio Ambiente): Brasil; 2005. URL Available in: http://pnqa.ana.gov.br/ Publicacao/RESOLUCAO CONAMA n 357.pdf

8. RESOLUÇÂO CONAMA no. 430, de 13 de maio de 2011. Dispõe sobre as condições e padrões de lançamento de efluentes, complementa e altera a Resolução n‥ 357, de 17 de março de 2005, do Conselho Nacional do Meio Ambiente-CONAMA. Diário Oficial da União. CONAMA (Conselho Nacional do Meio Ambiente); Brasil: 2011. URL Available in: http://www.labb.com.br/wpcontent/pdf/Resolucao CONAMA 430 11.pdf

9. RESOLUÇÂO CONAMA no . 413, de 26 de junho de 2009. Dispõe sobre o licenciamento ambiental da aquicultura, e dá outras providências. Diário Oficial da União. CONAMA (Conselho Nacional do Meio Ambiente): Brasil; 2009. URL Available in: http://www.icmbio.gov.br/cepsul/images/ stories/legislacao/Resolucao/2009/RES CONAMA_N413 2009.pdf

10. Silva NA. Caracterização dos impactos gerados pela piscicultura na qualidade da água: estudo de caso da bacia do rio Cuiabá, MT. [Mestrado em Física e Meio Ambiente]. Universidade Federal de Mato Grosso: Cuiabá, Brasil; 2007. http://www.dominiopublico.gov.br/pesquisa/ DetalheObraForm.do? select action $=\&$ co obra $=83787$

11. Lei Estadual no. 3.802, de 29 de agosto de 2012. Disciplina a atividade de aquicultura no Estado do Amazonas e dá outras providências. AMAZONAS. Diário Oficial do Estado do Amazonas: Manaus, Brasil; 2012. URL Available in: https://www.legisweb.com.br/legislacao/?id=244797 
12. Scorvo Filho JD, Cyrino JEP, Queiroz JF. Perspectivas para a adoção de BPM's na Aquicultura Brasileira. IN: Memórias do I Workshop Internacional para o Desenvolvimento de Boas Práticas de Manejo (BPMs) para a Aqüicultura. EMBRAPA; Brasil; 2007. URL Available in: http://www. cnpma.embrapa.br/download/documentos 70.pdf

13. Loix B. Effluent water treatment: Solids Removal. In: Manual on effluent treatment in aquaculture. Federation of European Aquaculture Producers. EU-Proj. (Six Framework Programme). AQUAETREAT: France, p. 31-43, 2007. URL Available in: https://archimer.ifremer.fr/doc/2006/ rapport-6496.pdf

14. Galvão JA. Rastreabilidade da cadeia produtiva do pescado: avaliação de parâmetros ambientais e sua influência na qualidade da matéria-prima destinada à indústria. [Tese Doutorado]. Universidade de São Paulo. Centro de Energia Nuclear na Agricultura: Piracicaba, Brasil; 2011. URL Available in: http://www.teses.usp.br/teses/disponiveis/64/64135/tde-30092011110439/pt-br.php

15. Pereira L, Mercante CTJ. A amônia nos sistemas de criação de peixes e seus efeitos sobre a qualidade da água. Boletim do Instituto de Pesca. 2005; 31(1):81-88. URL Available in: https:// www.pesca.sp.gov.br/Pereira 31_1.pdf

16. Boyd CE. Manejo do ciclo do ph para manter a saúde animal. In: Advocate Magazine Global Aquaculture Alliance, Alburn, Alabama. Ed. julho/agosto, p. 20-30, 2013. URL Available in: http://abccam.com.br/wp-content/uploads/2013/10/

17. Eler MN, Millani TJ. Métodos de estudos de sustentabilidade aplicados a aquicultura. R Bras Zootec. 2007; 36(Supl):33-44. DOI: http://dx.doi.org/10.1590/S1516-35982007001000004

18. Silva, MSGM, Losekann, ME, Hisano, H. Aquicultura: manejo e aproveitamento de efluentes. Documentos/Embrapa Meio Ambiente; 95. Jaguariúna, SP: Embrapa Meio Ambiente, 2013, 39p. URL Available in: https://www.infoteca.cnptia.embrapa.br/bitstream/doc/972692/1/Doc95. pdf

19. Abimorad EG, Castellani D. Qualidade da ração e manejo alimentar na sustentabilidade econômica e ambiental em empreendimentos aquícolas. Pesquisa \& Tecnologia. 2011; 8(1). http://www. aptaregional.sp.gov.br/acesse-os-artigos-pesquisa-e-tecnologia/edicao-2011/2011-janeirojunho/840-qualidade-da-racao-e-manejo-alimentar-na-sustentabilidade-economica-eambiental-em-empreendimentos-a/file.html?force download=1

20. Queiroz JF de, Boeira RC. Boas Práticas de Manejo (BPM's) para Reduzir o Acúmulo de Amônia na Aquicultura. Comunicado Técnico 44. Embrapa: Brasil; 2007. URL Available in: https://ainfo. cnptia.embrapa.br/digital/bitstream/CNPMA/7538/1/comunicado 44.pdf

21. Pivetta JR. Avaliação da qualidade do uso da água em piscicultura de água doce. [Tesis Mestrado em Agroecossistemas]. Universidade Federal de Santa Catarina: Santa Catarina, Florianópolis, Brasil; 2011. http://repositorio.ufsc.br/xmlui/handle/123456789/95286

22. Guo L, Li Z. Effects of nitrogen and phosphorus from fish cage-culture on the communities of a shallow lake in middle Yangtze River basin of China. Aquaculture. 2003; 226(1-4):201-212. https://doi.org/10.1016/S0044-8486(03)00478-2 